Железняк В.Н. За пределами себя: опыт поэтического экзистирования // Вестник ПНИПУ. Культура. История. Философия. Право. - 2018. - № 4. - С. 38-44. DOI: 10.15593/perm.kipf/2018.4.04

Zhelezniak V.N. Outside of Yourself: Experience of a Poetic Existing. Bulletin of PNRPU. Culture. History. Philosophy. Law, 2018, no. 4, pp. 38-44. DOI: 10.15593/perm.kipf/2018.4.04

DOI: $10.15593 /$ perm.kipf/2018.4.04

УДК 130.2:801

\title{
ЗА ПРЕДЕЛАМИ СЕБЯ: ОПЫТ ПОЭТИЧЕСКОГО ЭКЗИСТИРОВАНИЯ
}

\author{
В.Н. Железняк
}

Пермский национальный исследовательский политехнический университет, Пермь, Россия

ORCID: https://orcid.org/0000-0001-9071-0468

\begin{abstract}
Статья посвящена анализу поэтического текста. Если признавать за поэтическим текстом особый статус в языке, то практические опыты по «прояснению» поэтических произведений с помощью всего арсенала современного философского знания (в данном случае - феноменолого-экзистенциальной традиции в комбинации с герменевтическими установками и некоторыми новейшими онтологическими поисками) - по-прежнему остаются актуальной задачей. Завет Шеллинга об искусстве как органоне философии до сих пор реализован не очень полно и не очень серьезно. Перечисленные выше философские предпосылки и основания сосредоточены в конце статьи. Методология работы строится следующим образом: 1) автор (и читатель) воздерживаются от каких-либо предварительных установок относительно выбранных текстов; текст должен быть воспроизведен совершенно нейтрально, феноменологически чисто; 2) далее выявляются и маркируются основные мотивы, прямо звучащие в тексте стихотворения; 3) обнаруживается - в простом самораскрытии художественного явления - центральная поэтическая идея, реализованная в логике мотивов; 4) выявляется объективная «диалектика» движения мотивов, образующих серийную последовательность. Разумеется, важна не форма такого «самораскрытия», но его конкретный результат - практика выхода за пределы «сознания», «Я», «личности», «индивидуальности», «внутреннего мира» и т.п. Нас интересовал способ предельного эк-стазиса. Еще важнее то, что сознание, таким образом редуцированное и модифицированное, найдет по ту сторону мирового феномена. Разумеется, оно всегда находит то, что в этом феномене было явлено. Сферический греческий космос вещей или параллельные времена и пространства современной вселенной, - все это дано в одном ключе - мир без меня. Практикам достижения такого мира и посвящена данная статья.

Ключевые слова: анализ поэтического текста, мотив, экстазис, мировой феномен, экзистирование, вещи, мир, «Я», бытие, язык, лирика.
\end{abstract}

\section{OUTSIDE OF YOURSELF: EXPERIENCE OF A POETIC EXISTING}

\author{
Vladimir N. Zhelezniak \\ Perm National Research Polytechnic University, Perm, Russian Federation \\ ORCID: https://orcid.org/0000-0001-9071-0468
}

\begin{abstract}
Article is devoted to the analysis of the poetic text. Poetic text has the special status in language. Therefore practical experiments on "clearing" poetic works by means of the whole arsenal of modern philosophical knowledge (in this case - phenomenology, existential tradition, hermeneutics, the latest ontologicalsearch) - still remain a relevant task. Schelling's precept about art as a philosophy organon has not been realized up to now. Philosophical prerequisites listed above are given at the end of the article. The methodology of work is formed as follows: 1) the author (and the reader) keeps himself from any preliminary directives; the text has to be reproduced in the pure phenomenological aspect; 2) the main motives are to be revealed and marked; 3) the central poetic idea is found; 4) the objective "dialectics" of the motives movement forming the serial succession is being is uncovered. Certainly, it is not important the form of such "selfopening" but its definite result, namely the practice of overrunning the "consciousness", "I", "personality", "identity", "inner world". It is even more important what the reduced and modified consciousness will find on the other side of a world phenomenon. Naturally, it always finds what has been shown in this phenomenon. The Greek space or parallel times and spaces of the modern Universe - all is given in one criterion as the world without me. This article is also devoted to the practitioners of such world achievement.

Keywords: analysis of the poetic text, motive, ecstasy, world phenomenon, existential, things, world, "I", life, language, lyrics.
\end{abstract}

() Железняк Владимир Николаевич - доктор философских наук, профессор, заведующий кафедрой философии и права, e-mail: shlezo2@gmail.com. 
Перед нами стихотворение Арсения Тарковского. Стихотворение очень известное. Его читают актеры, поют барды, используют потерпевшие крах политики. Люди естественным образом, не мудрствуя лукаво, видят и чувствуют в нем нечто простое, до боли ясное и знакомое - некую пограничную, «экзистенциальную» ситуацию. Нам же приходится мудрствовать, повторяя старую истину о том, что искусство - органон философии.

Итак, перед нами текст стихотворения. Первая строка: «Я прощаюсь со всем, чем когда-то я был...». Мы намерены осуществить «анализ» этого стихотворения. В порядке прояснения нашего метода и его непосредственной практической реализации предпримем следующие шаги.

1. «Забудем» (любым способом: отвлечемся, сделаем вид, «редуцируем» еtс.) обо всем, что мы знали о А.А. Тарковском, что мы читали из его поэзии и проч.

2. Забудем о философских установках: об еросhе Гуссерля (даже если мы пытаемся применить нечто подобное), о хайдеггеровских прояснениях Гёльдерлина, о хронотопной герменевтике М.М. Бахтина и т.п.

3. Забудем все, что мы слышали о многосложной и многомудрой философии языка, об эксклюзивном значении поэтического слова и т.д.

4. Забудем о собственном опыте «экзистирования», о переживаниях по поводу бесконечных «начал», всегда обреченных на возвращение к тому, что истоком назвать трудно.

5. Забудем обо всех религиозных, этических, метафизических, культурно-исторических, антропологических и прочих основаниях нашего мировоззрения. Забудем обо всем, насколько это возможно. Есть только звучащая во внутреннем сознании строка:

Я прощаюсь со всем, чем когда-то я был...

То, что наш «ум» непосредственно усматривает в опыте переживания этой строки и последующих строк, мы будем называть мотивами - это очевидные смысло-интонационные движения, которые можно уподобить движениям музыкальных фраз, извлеченных из инструмента. Нельзя также упустить из виду, что наш ум со всеми его «трансцендентальными» структурами также редуцирован (насколько это возможно). Мотив в единстве с его смысловыми обертонами дан нам непосредственно - как некая реальность, в которой нельзя усомниться по причине отсутствия сомневающейся инстанции.

Итак, в нас звучит мотив прощания, а вслед за ним - ностальгической печали по прошедшей жизни, или, точнее, - по нашей личной истории, мотив «всего, что было со мной». Прощание - глубоко лирично, музыкально. Мы вспоминаем: прощание с другом, прощание с детством, прощание с дорогим покойником... Мы вспоминаем все, что было с нами, все, что случилось, прошло; все, что мы были склонны отождествить с нашей судьбой. Так что же, некто, лирический герой этих строк, говорит «прощай» собственной судьбе? Или судьба героя и состояла в том, чтобы подойти к границе, за которой действие судьбы заканчивается. Заканчивается личная индивидуальная история, заканчивается все, что наполняло жизнь, все, что он «ненавидел, любил». Выраженное в этих двух потрясающих строках прощание/расставание - очень серьезно, предельно серьезно. Такая серьезность и внятность последнего, абсолютного «прощай» указывает на то, что где-то рядом смерть. Без близости последней границы нашего здешнего, «мирского» существования, столь явный радикализм разрыва «со всем, чем когда-то я был» невозможен. И жизнь читателя со всем сладостно-горьким ее «контентом»- отлетает от него. Остается гордое заявление своей почти абсолютной, «буддийской» свободы, своей радикальной решимости на предельный разрыв.

Вторая двустрочная строфа противоположна первой: в ней доминирует не прошлое, которому сказано последнее прости, а «новая жизнь». Фундаментальный лирический мотив прощания сменяется смежным мотивом «новой жизни». Две темы заданы в одной антиномичной («сонат- 
ной») экспозиции, несмотря на то, что обе строфы представляют собой вариацию одного и того же. Доминантный акцент прошлой жизни противостоит доминанте новой жизни: лирический «бодхисаттва» радостно встречает звенящую пустоту нирваны. Оба двустрочных модуля образуют большую строфу, построенную на вариации мотива «новой жизни» (или конца прошлой).

Наш герой совлекает с себя «кожу вчерашнего дня». Это - не случайная метафора. Речь ведь идет не об играх с календарем. Речь идет о превращении ползающего отвратительного червя в летающее эльфоподобное существо. Это - лирический метаморфоз, за которым скрывается тоска по реальной, физической смене кожи, или, выражаясь более осторожно, - усталость души от надоевшей телесной оболочки, когда душа становится постылой себе самой.

Экспозиция антиномично связанных тем, выраженных в двух рифмованных элементах строфы, обрела целостность, завершена. Собственно, стихотворение на этом может быть завершено. Лирическое откровение, собственно, исчерпано. Дальше может быть развита только вариативная серия прозвучавших мотивов. Схема ее такова: третий двустрочный модуль вариация первого:

Я прощаюсь со всем, чем когда-то я был

И что я презирал, ненавидел, любил.

$\cdots$

Больше я от себя не желаю вестей

И прощаюсь с собою до мозга костей...

Вариации мотивов: «я, который решился на разрыв, на метаморфоз мозга, костей, кожи»«оставленный мною мир». Вариации акцентов: «новая жизнь» - «мир во всем его мирском измерении». Межстрочные вариативные связи организованы внутри и между большими четырехстрочными классическими строфами, в которых разрабатывается исходная экспозиция, образуя серию повторяющихся вариаций (эйдо-смыслового, а не эйдо-музыкального порядка, но в обоих случаях - серию интонационно-выразительных форм). Вариативная структура охватывает, таким образом, как последовательность строк в малых строфах, так и перекрестные отношения в движении двустрочных модулей, и серийные последовательности «полных» строф, в которых варьируется исходная поэтическая идея. Например, последовательность четных двустрочных элементов:

Начинается новая жизнь для меня,

И прощаюсь я с кожей вчерашнего дня.

$\cdots$

И уже, наконец, над собою стою,

Отделяю постылую душу мою...

$\ldots$

Здравствуй, здравствуй, моя ледяная броня,

Здравствуй, хлеб без меня и вино без меня...

...

Вариативно-сериальная структура поэтического текста очень важна для наших медитаций. Она говорит о том, что поэт стремится выразить одну единственную идею. Поэт - медиум эстетического выражения. - Чистый, совершенный медиум («чище» может быть только музыка, лишенная материи языка). В этой системе повторений мы находим вариацию:

Отделяю постылую душу мою...

$\ldots$

Здравствуй хлеб без меня и вино без меня... 
Но душа и святые дары - не простые принадлежности мирского существования. Душа может опостылеть, если она слита с обмирщенным сознанием. Но - святые дары? Мотив прощания с миром достигает здесь парадоксального порядка, захватывая и сферу трансцендентального, поскольку она символически присутствует в мировом феномене. Антитезы земного существования - божественное и мирское, «бабочки дня» и «сновидения ночи» - в равной степени исчезают в этой великой прокламации отказа. Резигнации подвергается и сам герой. Появляется мотив поэтического двойничества:

В пустоте оставляю себя самого,

Равнодушно смотрю на себя - на него.

Мы осознаем, что все это время имели дело со странным взглядом. В самом деле, кто-то смотрит на себя - то есть на него, - уже не на себя, а на кого-то другого, опостылевшего и чужого. Появляется некто - некий апофатический «субъект», не имеющий положительных определений, только продукт отрицания-отказа. Отказ распространяется и на миссию поэта даровать слово всему сущему. Поэт все видит и все слышит, но отказывается транслировать этот опыт в мир. Отказ от дара речи - последний мотив, представленный в последних строках стихотворения. Цена за достигнутое просветление столь высока, а его ценность с позиций социальной значимости столь сомнительна, что может смутить любую добродетель. Но и подобные сомнения - «теперь без меня».

Прочитав эти строки, мы вместе с героем вышли за пределы своего «Я», сознания, социума, индивидуальности, мирского и сакрального. Мы вышли за пределы человеческого опыта - пресловутого «здесь-бытия». «Мы» - простой, ясный, звеняще пустой и чистый медиум «при», «наряду» и «рядом» со всем сущим:

Я читаю страницы неписанных книг,

Слышу круглого яблока круглый язык,

Слышу белого облака белую речь...

Яблоко и облако отсылают нас к другому поэтическому свидетельству другого поэта.

Замедленное яблоко не спит,

украденное облако не тает -

в другие времена оно летит,

а в этих временах оно летает

Иван Жданов - поэт другой «школы», другого «направления». Но лира его охвачена такой же онтологической тоской. И яблоко, и облако - космические объекты, замедляющиеся и ускоряющиеся в параллельных временах. Русские поэты жаждут выйти в космос - греческий, ортодоксальный, начинающийся прямо за порогом. Собственно, метафорика их поэтического языка выражает «сознание», стоящее рядом с вещью. Точнее говоря, «сознание» и язык модифицированы таким образом, что первое становится пустым, медиальным, а второй переживает разрушение собственного дискурса под тяжестью метафорических переносов.

Стихотворение И. Жданова пронизано не столько космическими предчувствиями, сколько прямыми космическими ощущениями. Стихотворение имеет трехстрофную структуру (чрезвычайно распространенную, представляющую собой как бы особый жанр лирической миниатюры). В этом случае чаще всего первые две строфы представляют собой антитезы, а третья разрешает противоречие. Замедленное яблоко и украденное облако - вводные образы, не связанные никакими формальными условиями. Попробуем заменить оба «странных» эпитета на противоположные: ускоренное яблоко не спит, дарованное облако не тает. Наверное, можно и так. Дело, возможно, не в этих определениях с точки зрения их значений и «авторского замыс- 
ла», а в том, что они вообще приписаны вещам (которые замедлены, ускорены, отброшены, привязаны, украдены, найдены, повреждены, благоденствуют и т.п.). С вещами что-то происходит, поэтому они не спят, тают или возникают, плывут или тонут... Можно подумать, что с яблоком/облаком что-то случилось в результате метафизической катастрофы - внезапного замедления времени например, в результате чего яблоко не может уснуть, а облако растаять. Однако очевидно, что подобные гадания уводят нас от поэзии. Замедленное яблоко - не спит, а украденное облако - не тает. Вот все, о чем здесь сказано (причем, эти наши тире не могут обозначать каких-либо причинных отношений). Объявлена простая констатация, приведенная в движение сомнамбулическими строками о различии времен, где летят и летают.

Вторая строфа - парадиз мироздания, жест творения. Туда улетают неукраденные облака, которые летают в «этих временах». Третья строфа: возвращение обратно в мир, пораженный отсутствием истаявших облаков. Поэтическая «триада», несомненно, налицо. Тем не менее сколько-нибудь серьезное мудрствование по поводу расшифровки причудливых образов этого произведения - сомнительно. Сам поэт читает свои стихи в манере, позволяющей доверительно проговаривать синтаксис поэтической речи, как будто «поэтическая темнота» не имеет отношения к его логике. Это создает впечатление ясности (настоящий поэтический мрак и должен быть грамматически - и, следовательно, логически - ясным). Можно довериться музыке и мелосу этих стихов. Можно представить себе тающие в зените облака. Можно поискать и другие приемы. Но одно следует определить строго: речь в этом стихотворении идет о мире и космосе, где поэта и нас в качестве «табельных» субъектов, чья «субъективность» определяет причудливую образность поэтического видения, - нет и изначально не было.

Опыт выхода за пределы сознания, свидетелями которого мы только что были, вполне позитивен и реален. И мы, простые люди, далекие от огня поэтического гения и заповедей Диотимы, вполне можем освоить технологически доступные практики сознания, позволяющие хотя бы частично, хотя бы на время избавиться от «опостылевшей» субъективности. Сознание вполне может быть модифицировано таким образом, чтобы из моего «Я» превратиться в простое сознание яблока, облака, людей, рыб и камней, листвы и травы. Поэтическая (художественная) редукция направлена прямо противоположным образом, нежели феноменологическая - от «Я» к вещам, за пределы сознания, пусть и за счет метафорической деструкции языка. Ключевые инстанции «сознания»: воображение, суждение (рассудок), поле апперцепции, чувственность, эйдетические проекции, голосовой аппарат, мимическая пластика prosopon и т.п. - сами могут представлять собой вещи, которые мы нашли, распрощавшись с собой. Смысл полученного нами урока состоит в том, что радикально покинув наше «Я» и, соответственно, выйдя за пределы мирового феномена, мы в известной мере выходим и за пределы макро-хронотопа. Теперь объектом нашего созерцания и медитации может быть

не облако, которое летит,

а облако, которое летает.

Опыт поэзии свидетельствует, что мы в некотором смысле можем покинуть наше «Я» и выйти в мир. Было бы наивно усматривать в этом какую бы то ни было мистику или идеализм. Наше сознание устроено таким образом, что способно выносить нас во вне себя за пределы психического солипсизма, за пределы наличного тела, за пределы Dasein, к вещам и за пределы вещей. Сознание в своей негативной стихии не только не заслоняет от нас бытие, но открывает его нам, будучи его чистым медиумом. По крайней мере все это имеет место в функции «эстетического отношения» (поэтического, «сочиняющего» экстазиса). Равно как и подобный ход мыслей, и практическая технология анализа текста находит опору 
в самых разных литературных аналогиях, в бесконечном лабиринте ссылок и отсылок, в методологических аксиомах и параллельных темах.

Идея обратной редукции, которая давала о себе знать в нашем анализе, восходит к «Meditationes...» Декарта, где мы находим не только путь к чистому cogito, но и обратное движение от чистой мысли, чистой спонтанности «Я» - к чувственности, вплоть до телесных манипуляций и локомоций $[1$, с. 59, 63]. И у Гуссерля при всем его трансцендентализме сохраняется верность интенциональной направленности сознания, и более того: «Мое живое тело, как соотнесенное с самим собой, обладает способом своей данности в качестве центрального «здесь»...» [2, с. 226]. Это ошеломляюще просто: мы самым естественным образом находимся между, как минимум, собственным телом и другими телами, и, следовательно, наше «Я» интерсубъективно столь же естественным образом. Мы не говорим о концепте идеи Гуссерля, но можем - в параллель - упомянуть о знаменитом са̀мое само̀ А.Ф. Лосева: «Беспредикатное са̀мое само̀ есть великая простота сознания и бытия» [3, с. 221]. С так открывающейся нам «сущностью» мы напрямую сталкивались в наших поэтических погружениях. В. Подорога вряд ли испытал большее влияние трактатов А. Лосева о сути вещей, но общая тенденция - за пределы сознания, за пределы фундаментальных дихотомий старой метафизики вполне разделяется и им. Так, со ссылкой на Б. Латура он говорит: «Нужно отказаться от веры в эту ложную мифологию Нового времени и вернуться к самим вещзам» [4, с. 39]. В этом же направлении движется и современная «объектно ориентированная» мысль. Со ссылкой на Г. Хармана С. Шавиро пишет: «Вещи активны и интерактивны далеко за пределами какого-либо соизмеримого с нами присутствия» [5, с. 132].

Перейдем к философской поэтике. Нам случалось писать о сериальной структуре лирических произведений $[6,7]$. Ж. Делёз демонстрировал, как отдельная любовная история в романах Пруста выстраивается в форме серии, и все повторения любви - сериальны. (Серия приближается к закону, а любовь к концу.) [8, с. 96-98]. Т. Адорно в связи с анализом творчества А. Веберна спрашивал: «Что нужно сделать, чтобы звук, идущий от души, приобрел объективную необходимость и непреложность в тотальной сквозной конструкции...» [10, с. 193]. С этой «объективной необходимостью» произошла сложная история. Вендель Кретчмар, персонаж романа «Доктор Фаустус» Т. Манна, раскрывал юным Леверкюну и Цайтблому основы адорновской философии музыки на примере позднего Бетховена: «Незатронутая и не преображенная субъективностью конвенция... в обнаженности или, можно было бы сказать, в надменности и я-покинутости...» (Ausgeblassenheit, Ich-Verlassenheit С. Апт и Н. Ман переводили как «опустошенность» и «отъединенность от я») [11, с. 73]. Специфическая надменность и япокинутость гения - нечто подобное мы видели в нашем примере. А.Е. Махов в конце своей замечательной книги описывает заочную полемику М. Юдиной с Т. Адорно (на фоне ее переписки с М.М. Бахтиным). Пианистка, говорит А.Е. Махов, видимо, просто не замечала «мудрости» философа. Но в одном они могли сойтись: произведение - выход, прорыв в некое в этой реальности не находящееся место, «в некий трансцендентный ландшафт» [12, с. 205].

В заключение следует упомянуть о современном модерне в искусстве. Разумеется, в нем присутствует разное. Но основная тенденция, связанная с «революцией» М. Дюшана и историей реди-мейда, в высшей степени характерна: вещь становится вне всех конвенциональных рамок, порождая тем самым массу тяжелых негативных следствий (для упомянутых конвенций) $[13$, с. 36]. Поклонник Дюшана Дж. Кейдж аналогично жил и творил за пределами собственно «музыки»: «Теперь мне не нужно фортепьяно. У меня есть Шестая авеню, ее звуки» [14, с. 45]. Если не подходить ко всему этому вульгарно, то нам откроется наполненная бесчисленными вещами и звуками реальность, где нас совершено нет, полностью нет, абсолютно нет... 


\section{Список литературы}

1. Декарт Р. Соч.: в 2 т. - М.: Мысль, 1994. - 640 с.

2. Гуссерль Э. Картезианские размышления. - СПб.: Наука: Ювента, 1998. - 316 с.

3. Лосев А.Ф. Самое само // Лосев А.Ф. Вещь и имя. Самое само. - СПб.: Изд-во Олега Абышко, 2016. - 576 с.

4. Подорога В. Вопрос о вещи. Опыты по аналитической антропологии. - М.: Грюндриссе, 2016. $-348 \mathrm{c}$.

5. Шавиро С. Вселенная вещей // Логос. - 2017. - № 3. - С. 127-152.

6. Железняк В.Н. Вечно другой (к вопросу о сериально-вариационной технике в современной поэзии) // Я и другой в пространстве текста: межвуз. сб. науч. тр. - Пермь-Любляна, 2009. - C. 110-116.

7. Железняк В. Н. Сериальная строфика в поэзии И. Жданова // Филолошки студии. Скопье - Пермь - Любляна - Загреб, 2007. - С. 39-42.

8. Делёз Ж. Марсель Пруст и знаки. - СПб.: Алетейя, 1999. - 186 с.

9. Хайдеггер М. Разъяснения к поэзии Гельдерлина. - СПб.: Академический проект, 2003. $-320 \mathrm{c}$.

10. Адорно Теодор В. Избранное: Социология музыки. - М.: СПб.: Университетская книга, 1998. -445 с.

11. Mann T. Doktor Faustus. - Aufbau-Verlag Berlin und Weimar, 1975. - 716 S.

12. Махов A.E. Musica literaria: идея словесной музыки в европейской поэтике. - М.: Intrada, 2005. - $244 \mathrm{c}$.

13. Дюв Т. Де. Именем искусства. К археологии современности. - М.: Изд. дом Высшей школы экономики, 2014. - 192 с.

14. Разговоры с Кейджем. - М.: Ад Маргинем Пресс, 2015. - 400 с.

\section{References}

1. Dekart R. Sochineniia v 2 tomakh [Works in two volumes]. Moscow, Mysl`, 1994, 640 p.

2. Gusserl E. Kartezianskie razmyshleniia [Cartesian reflections]. Saint Petersburg, «Nauka», «luventa», pp. 1998-316.

3. Losev A.F. Samoe samo [Itself]. Saint Petersburg, izdatel`stvo Olega Abyshko, 2016, 576 p.

4. Podoroga V. Vopros o veshchi. Opyty po analiticheskoi antropologii [Question about things. Experiments in analytical anthropology]. Moscow, Griundrisse, 2016, 348 p.

5. Shaviro S. Vselennaia veshchei [Universe of things]. Logos, 2017, no. 3, pp. 127-152.

6. Zhelezniak V.N. Vechno drugoi (k voprosu o serial'no-variatsionnoi tekhnike v sovremennoi poezii) [Forever another (on the issue of serial-variation technique in modern poetry)]. Perm 'Liubliana, 2009, pp. 110-116.

7. Zhelezniak V.N. Serial`naia strofika v poezii I. Zhdanova [Serial stanza in the poetry of I. Zhdanov]. Filoloshki studii. Skop`e Perm` - Liubliana - Zagreb, 2007, pp. 39-42.

8. Deleuze J. Marsel’ Prust i znaki [Marcel Proust and signs]. Saint Petersburg, Aleteiia, 1999, 186 p.

9. Heidegger M. Raziasneniia k poezii gel derlina [Clarifications to the poetry of Hölderlin]. Saint Petersburg, Akademicheskii proekt, 2003, $320 \mathrm{p}$.

10. Adorno T. V.. Izbrannoe: Sotsiologiia muzyki [Adorno. Selected: Sociology of music]. Moscow; Saint Petersburg, Universitetskaia kniga, 1998, 445 p.

11. Mann T. Doktor Faustus. Aufbau-Verlag Berlin und Weimar, 1975, $716 \mathrm{~S}$.

12. Makhov A.E. Musica literaria: ideia slovesnoi muzyki v evropeiskoi poetike [Musica literaria: the idea of verbal music in european poetics]. Moscow, Intrada, 2005, 244 p.

13. Duve T. de. Imenem iskusstva. K arkheologii sovremennosti [The name of art. To the archeology of modernity]. Moscow, IVysshaia shkola ekonomiki, 2014, 192 p.

14. Razgovory s Keidzhem [Talk with Cage]. Moscow, Ad Marginem Press, 2015, 400 p.

Получено: 20.08.2018

Принято к печати: 20.10.2018 